\title{
Climate, a crossroads negotiation
}

\author{
Michel Rogalski \\ 115 Rue du Cherche-Midi, \\ 75006 Paris, France \\ Email: rogalski.michel@orange.fr
}

\begin{abstract}
Conscious for 30 years of the prospect of climatic reheating and the harsh changes associated with it, the international community has tried to set up a world climatic architecture likely to slow down and contain, at acceptable levels, the foreseeable evolution. A stack of agreements (Rio 92, Kyoto Protocol, Copenhagen and Cancun Summits) resulted from these international negotiations, mixing scientific controversies, responsible factors, uncertainties about national consequences and questions on the coordination of economic instruments which have to be at the same time effective and right. These negotiations reveal a world undergoing fast change, and the persistence of a North-South antagonism. They crystallise different visions concerning the apprehension about time and strongly question the models of development which have been set up.
\end{abstract}

Keywords: negotiations; Kyoto Protocol; climate change; world climatic architecture.

Reference to this paper should be made as follows: Rogalski, M. (2012) 'Climate, a crossroads negotiation', Atoms for Peace: An International Journal, Vol. 3, No. 3, pp.183-196.

Biographical notes: Michel Rogalski is an Economist and Researcher at the CIRED (International Research Center on Environment and Development), linked with CNRS and EHESS (School of Advanced Social Studies) in Paris. He taught at the University of Paris 1 and at the EHESS. He was associated with the Experts Group of United Nations about the Relations between Disarmament and Development, and was a member of the working group on North-South Commission of the General Commissariat of Plan (Paris). He was Scientific Director of the review Mondes en développement (Paris-Bruxelles). $\mathrm{He}$ is Director of the French review Recherches Internationales.

\section{Introduction}

For about 30 years, international life has been punctuated by Summits holding the planet in suspense. Suspense and overexposure by the media are the rules, and accompany the ballet organised by the Heads of State and decision makers in the world. More felt and discrete, one finds there also the presence of lobbies coming from the business world and industry, or more significantly the representatives of the sensitive ecologist in the civil society, in particular their large international NGOs. What is discussed here is the future of the climate with at stake the possibility of continuation of all human activity on the planet; because man discovered that since the birth of industrialisation, he has been able to upset the scheduling of planetary balances to a point which risks the survival of his 
species. It includes even the entry of humanity in the era of the anthropogenic (Crutzen and Stoermer, 2000), succeeding the revolution of the Neolithic era where more than 10,000 years marked the passage of hunter-gatherers to the world of agriculture and breeding, the conditions for the beginning of a more sedentary way of life.

Thus, the climate negotiations are set up starting from the decisions at the Earth Summit in Rio in 1992, and regularly bring together their participants from Kyoto to Cancun going through Bali, Bangkok, Buenos Aires, The Hague, Poznan or Copenhagen and Durban. Gradually, an international architecture builds and weaves the features for a mode of international coordination about climate. The world is organised by international agreements without which international life would be impossible. The AITA governs air transport by associating manufacturers of planes, airports, firms and states, and codifies rules contributing to the safety of the passengers. The International Postal Union ensures the conditions for the distribution of mail all over the planet. The IAEA gives, according to strict rules, access to nuclear energy to many countries which, because of lack of technological means and scientists, would be deprived of it, but is authorised to control the absence of diversion to military devices. One could multiply the evolution of this type of agreement contributing to organise life on a planetary scale. And of course when, from the start, a problem concerns the world, because no country can claim to escape from its consequences, the need for a climatic agreement in fact becomes a necessity, urgent if one listens to the words of the scientists.

\section{Facts of the case}

Since the Copenhagen conference, and largely because of the media, the question of climatic change became defined as the set of themes about durable development, within the registered framework.

From the 1980s climatologists unanimously noted a tendency to climatic reheating, with a notable rise from the industrial period. They point out the strong probability of human responsibility through greenhouse gas (GG) emissions concentrating in the atmosphere (mainly methane and carbon dioxide). The use of resources of fossil origin (coal, oil and natural gas), with a high percentage of carbon, is likely to be the cause. This average rise in temperature will, in around 50 or a 100 years, cause climatic disturbances likely to generate damage unbearable for the continuation of human activity.

In 1988, the system of the United Nations, alerted to the dangers of these evolutionary changes, set up an organisation, the Intergovernmental Panel of Climate Change (IPCC), to account to governments concerning climate evolution, and to suggest actions which it would be advisable to take in order to face the problem and adapt to it. It thus acted, starting from earlier scientific work, to take stock of acquired knowledge and to formulate recommendations. Located between scientists and decision makers, the Panel constituted originally an organisation of hybrid status, working under the gaze of the lobbies, public opinion and the media. Over the years, the IPCC has provided reports increasingly expanded and precise on the certainty of the entropic origin of the disturbance, but paradoxically increasingly dubious on the extent of the reheating and the localisations or the forms of its demonstration. ${ }^{1}$ For example, the fork of evolution of average temperature, as one of the elements initially neglected, will be expanded, like the role of the clouds or that of the oceans, in climatic mechanics. In the same way, the rise of the sea level remains dependent on the polar glaciers whose evolution remains badly 
controlled. In fact, the more one advances in knowledge of the climate, the more one discovers feedbacks, initially abandoned, which contribute to introduce more uncertainty into the models. On several occasions, the recommendations were formulated to insist on the urgency of the necessary actions, and the potential cost generated by any delay to their implementation (cf. Stern, 2007). Certain assertions of the reports will sometimes be disputed and corrected but never being discarded until their major significance is called into question. Even the concept of average temperature of the sphere was questioned by many geographers, a little suspicious and reluctant with respect to the concept of sustainable development (Brunel and Pitte, 2010). They argued that, from the point of view of their discipline, the division of the planet into 100 kilometres sided squares did not offer a fine enough resolution to anticipate the evolution of microclimates which make sense only on much more modest dimensions. The whole of these criticisms contributed to delegitimise, for a time, the word of the IPCC on the anthropogenic origin of climatic change, in particular at the time of the Copenhagen conference.

Today, the scientific controversy has largely calmed down as well on the mechanism of the effect of GGs on climatic tendencies. ${ }^{2}$ Nevertheless, controversy remains on the size of the human contribution to the reheating, i.e. on where to fix the cursor between anthropogenic and natural causes. ${ }^{3}$ To get the right answers on the origin is indeed important. If the cause is primarily natural, that is to say of solar origin, it is mainly a question of adapting, and of helping the poorest and most vulnerable countries to do it, in particular by world transfers of financing of infrastructures. If the human origin is dominant, then it will be necessary to drastically lower GG emissions, and to think about the methods of a transition towards an economy capable of being free from resources of fossil origin. But in both cases, it will be necessary to act. The more one can lower, the less one will need to adapt and vice versa. The debate also relates to the modes of effective international coordination, the criteria, and the usable instruments of economic analysis to allow the equitable implication of the various states and acceptance from public opinion about the costs associated with the necessary measurements.

An agreement was reached to accept that by 2100 , it is important to contain the rise in the average temperature of the sphere by $+2{ }^{\circ} \mathrm{C}$ maximum. Beyond this rise, the consequences would be considered to be unbearable in terms of damage and disorganisation of social life. The problems most usually advanced are as follows:

- change in the distribution of rainfall

- melting of the ice-floes and retreat of the glaciers

- advancement of germination in agriculture

- cyclones and typhoons becoming more frequent, violent and unforeseeable

- $\quad$ rise of the sea level (40 $\mathrm{cm}$ to several metres according to predictions).

These tendencies related to the rise in temperature will be accentuated and give rise to unforeseeable, brutal events of great amplitude. One can envisage falls in agricultural output in the Tropical zone, a reduction in water resources (according to region), coastal and deltaic floods, the return of chronic diseases (cholera, malaria) and displacement of important populations. There would appear a new concept - that of climatic refugees. The prediction for each country is still uncertain, but all would be affected if only because of the disorganisation which would occur. 
The maximum figure of $+2^{\circ} \mathrm{C}$ constitutes the reference. Island States would like it even lower at $+1.5^{\circ} \mathrm{C}$. From there arises the necessary reduction in emissions of GGs and thus the extent of the measures to be taken. It is the headline figure which today is not allowed to be passed. It crystallises the level of effort necessary and dictates the level of the constraint. But today this figure seems completely overtaken by the insufficiency of commitments, particularly after Copenhagen conference. The world models are currently gauged on assumptions which turn around $+3.5^{\circ}$ to $+4^{\circ} \mathrm{C}$. This maximum figure of $+2^{\circ} \mathrm{C}$ took on a value-fetish and was cemented at the time of G8 Summit in 2008, then confirmed by the signatories of Copenhagen conference at the end of 2009, and confirmed again in Cancun. The negotiators must integrate all the constraints, since this fixes the extent of necessary measures regarding the reduction of emissions. But its weakness is to be also partly a political and diplomatic figure, likely to be renegotiated. History showed that the concept of supportability was prone to fluctuations and that its threshold was not inevitably perceived identically in any part of the planet. ${ }^{4}$

\section{Specificities of the climatic question}

\subsection{Climate, a common good}

From the beginning we are faced with global problems, where the threat relates to the planetary ecosystem, disturbances of which will certainly affect (differently) all the inhabitants of Earth and that each one contributes to influencing this. One cannot be precise about the impact on any particular area, but it is known that they will be variously affected and that even those less affected will undergo collateral effects. It is thus not possible to hope to withdraw our token from the game, imagining that we are not concerned.

But GGs do not have a National flag or a Company logo which would identify them. It thus does not matter who emits them or from where they are emitted. The only thing that counts is the emitted quantity. Let us maintain this point of view that Mr Climate is worried only by the quantity of emitted GGs, and not knowing who emits them or what they cost, whereas these are often the central points of all negotiation. It is, consequently, tempting to adopt the strategy of the 'stowaway', and to abstract oneself from the collective effort, hoping to profit from the result obtained thanks to the efforts of others.

\subsection{The weight of uncertainty}

The research launched during the last 30 years confirmed and specified the strong human origin of the forecast climatic upheaval. At the same time, this work revealed the extreme complexity of the tangle of causalities, the mechanisms implemented, and the phenomena of potential feedbacks, the possible ruptures, the significant thresholds and especially the completion dates. This brought us to speak not about planetary reheating, but of climatic change the springboard of which will be the increase in the average temperature, resulting in changes affecting the climate everywhere, but in different ways (Schelling, 2010). We are dealing with a new field of study, requiring the cooperation of multiple disciplines in rapid upheaval. And in addition, no accumulated human experience can help us to say precisely how our lives will be upset in 50 or 100 years when the changes start to take effects. Without risk of being mistaken, one can suppose that we will not all be equal in these upheavals, although living on the same planet. Probably the Southern countries, more climatically dependant because of the importance of their agricultural 
activities, will be hit harder, and will have less means to cope. The perception of the threat is not identical from one end of the planet to the other. We are thus confronted with a rising tide of uncertainties.

To that is added the hope, engendered by climatic engineering, of being able to 'manufacture' climate, and thus to oppose the threatening evolution. ${ }^{5}$ That can appear like science fiction, but we know that the military has probably worked on that subject for years, from a less peaceful point of view, and that climatic weapons will, one day, be part of their panoply, although the use of the climate is in theory prohibited in conflicts. The prospect of the capture and sequestration of carbon which would make energies of fossil origin less harmful, and which is also connected with the techniques of climatic engineering is already the subject of advanced research. Cooperation has already developed around these stakes, particularly between the USA and China, ${ }^{6}$ and would obviously interest India, Australia and Canada. We understand the interest expressed in these techniques of the countries equipped with coal reserves of more than 100 years, and which would be opening up the prospect for their exploitation under climate-compatible conditions. In giving the illusion of being able to face these threats, these techniques contribute to delay the moment of the start of action likely to be directed towards a decarbonised economy. But, of course, such recourse is always necessary and proves to be effective; we can hardly see how the decision to stop such research could be made. These uncertainties, which even accompany the subject of climate negotiations, weaken the possibility of reaching for an agreement. But other questions give a special character to these negotiations.

\subsection{The concern about time}

We are in the presence of temporal dimensions which are not of the same nature. There is a chronological hiatus between the time of governmental action and the one of the environment. The result of the action undertaken, especially if it is expensive, must be perceptible within the scope of the political mandate in place, which is subject to reelection. There is a telescoping in the timing. The action on climate supposes immediate decisions, the effects of which will be felt at best in ten years, taking into account inertia specific to the mechanism of the greenhouse effect. It does not belong to the natural timescale of the political decision maker. This phenomenon is worsened because the lengthening of the deadlines is such that nobody may perceive the benefit of a policy early, but everybody is victim of the inaction of those preceding us. In this way, time intervenes in a second way because it crystallises the memory of what happened and reveals, through a manifest traceability, differentiated responsibilities. It thus causes to emerge the question of climatic responsibility, a topic which will quickly become central in international negotiations. Finally, time testifies to the birth of the climatic question because it brings back the old dilemma of arbitration between the present and the future. According to our inclinations, one will be preferred to the other. And if the scientist can inform us about the consequences of our acts, it is not up to him to choose for us in this matter. ${ }^{7}$ In short, we are at the heart of an old question, the one of the sacrifice of a generation for a brighter future. Inter-generation solidarity is also failing in another way. Does the generation which lived through the difficult 20th century also have to carry the cost of the evils of the 21st even if they were, without knowing it, part of the problem? All reflection on the actions undertaken to face climatic change is carrying such problems. Even posed in administrative terms of the profitability or effectiveness of 
spending today to adapt to the future climatic change, the question will remain held by this concern. And the answer will largely come from the place where one has put the cursor to determine the present and the future. This debate on temporalities will itself be strongly overcome by the one on space. Can't the mobilised means immediately relieve the other evils affecting the planet? Space solidarity will be used as a missile to torpedo inter-generation solidarity. ${ }^{8}$ It is thus not abnormal that the debate on the climatic change becomes a crossroads crystallising many questions as in the long term; it is an upheaval in our ways of producing and consuming and in our life styles. That can only usher strongly established interests.

To break the omnipresence of the temporal dimension in the climatic question, it would have to be shown that from emissions of GGs there would be immediate harmful effects, on health for example (cardiopulmonary diseases, cancers, etc.), that action to be undertaken would be of continuing benefit and that any delay in its implementation would be likely to be punished. To circumvent the weight of the energy lobbies, various commissions tried, in the USA particularly, to make GG emissions a problem of pollution and public health; without notable consequences. ${ }^{9}$

\subsection{Differentiated responsibilities}

Very early, and rightly, the Southern countries made the point that GG emissions accumulated in the atmosphere and at the origin of their concentration, they were very little ownership and responsibility. Even today, they added, they were far from being the principal transmitters, and that moreover, averaged per capita of population, their contribution was modest. The industrialised countries thus had to accept the principle of common but differentiated responsibility. This was enacted at the Kyoto Protocol signed in 1997.

Concretely, that meant that developed countries were to draw the conclusion of admitting the responsibility which fell to them in the international effort. This point is regarded as an important asset for the Southern countries. It is the only international treaty referring to this concept and this is why the Southern countries are very attached to it. Thus, since 1997, they propose three central claims in the negotiations: to benefit from a moratorium, to receive financial compensation to adapt themselves and to engage objectives less ambitious than the Northern countries. Whereas the industrialised countries are committed, by Kyoto in 1997, to reduce their emissions, the Southern countries will have to join the effort only in 2013. In the same way, Copenhagen confirms the engagement of the Northern countries to provide funds to finance the efforts of the Southern countries to adapt. It is also accepted today that the Southern countries will not be held to reduce their emissions in absolute quantities, but rather to lower the curve of their rise, in respect of their requirement for development; encouraging them to consider trajectories, especially as they will be fast growing like the large emergent countries. The recognition of a common responsibility opens the door to treatments and differentiated commitments which can only be additional sources of complexity in the negotiations but register nevertheless as a necessarily pragmatic and realistic step, unless making any agreement impossible.

These questions bring us back to more complex debates on justice and equity concepts in international order. Can the idea of historical responsibility be anachronistic? Can one be held responsible today for an action and its annoying effects of which nobody imagined at the time it was done? Should we count the accumulated emissions or worry about those to come? How to take into account the size of the countries, their population, 
their level of prosperity and the dynamics of their growth? The debate on these criteria accompanies the negotiations and can slow down their progress. But let us never forget that to have a successful agreement and the commitments which have been entered into respected, it is necessary that each country finds their interests there. It is necessary also that it has the capacity to honour the outstanding commitments and thus that the forms of globalisation and the exercise of world governorship do not undermine all possibility. No international agreement can be applied if the entities' signatories are too weakened to make it effective. In the intergovernmental one, the basic link is the state Nation. If it is undermined, the chain breaks.

\subsection{A world in rapid change}

These negotiations have taken place over the last 20 years, a period during which not only was scientific knowledge clarified but especially during which the world experienced true upheavals to the point of causing to emerge a new geopolitical deal which makes relatively obsolete the place occupied by various countries in the world scene. The ratios of power were reorganised. A large country, China, aspires to become the equal of the USA, weaving increasingly close links. A group of countries - India, Brazil and South Africa - weighs strongly on the world scene. These countries are at the same time trying to involve the whole of the Third World and to represent it, while seeking to see them recognised as of greater importance, with the attributes associated with that. The Northern countries try to separate these large emergent countries from the remainder of the Third World and to give them more responsibility in the climatic stakes, by making them contribute to the financing of the assistance given to the most fragile countries.

The climatic question emerges in a changing world, at a time when the great powers of the Third World see greater growth rates and are in emergence, whereas the industrialised world enters an enduring economic languor. Thus, the climate negotiations are more and more exercised by the North-South fracture and become, in the absence of other institutionalised places, one of the rare enclosures where the great questions about development can be argued in a concrete way (cf. Dahan et al., 2010). The South, particularly the emergent countries, can imagine that the decisions taken about climate will contribute to continue the old way and block its development when it is in rapid growth. ${ }^{10}$ It is understood that, in a world changing at such great speed, protracted negotiating positions can embrace new situations and find positions reversed, and how, for example, the significance of dates which are used as reference marks to quantify the emissions of GGs can quickly change. In terms of rise of power of certain countries and the correspondingly fast rise of their emissions - those of China today exceed those of the USA - it is all the climatic hierarchy which is forced to the point of asking itself about the sustainability of the base foundation of the Kyoto Protocol distinguishing the 'countries from Appendix 1' from the others.

\section{Which international architecture?}

All construction of this nature crystallises recurring debates on the order, justice and equity of international concepts. The discussed criteria will return, consciously or not, to this or that doctrinal school of thought which will borrow from reference marks: cosmopolitan approach or internationalist approach. 
Cosmopolitanism has always assumed the primacy of the citizen of the world over that of membership of the nation. The principle of absolute equality of men, independent of their residence or birthplace, is strongly reaffirmed and their membership in a country could not be derogatory. Rights and efforts must thus be equally distributed.

On the other hand, internationalist justice proceeds on the sovereign equality of States which are the only negotiating parts. The rights of individuals are determined within the borders of each country. Sovereign equality does not make any obstacle for the recognition of asymmetries in situations that the right of development proposes to fight by compensation inequalities. The United Nations system lies within this conceptual scope.

The world climatic scene is pulled about constantly between these two systems. And one should not be astonished that States with worrying sovereignty, like India and China, can claim principles of cosmopolitanism if that advances their interests. So it is the reference for calculating the emissions per capita, taking into account the importance of their population that would rightly place them as having the most important emissions in the world. Since the Rio Conference the negotiations about climate have been organised between countries and not through the forum of citizens' world assembly, but the place of worldwide society is more prominent. The presence - even the monitoring - of public opinions, media and scientific community constitutes a characteristic feature of it. We should not consequently be astonished that bitterly discussed criteria come from various designs.

Therefore, the States are getting involved, and the techniques used to advance discussions sometimes look like the tricks of carpet merchants. In Kyoto, whereas the commitments which were going to be discussed were only related to the countries of Appendix 1 (industrialised countries and ex-countries from the East), it was undertaken to have other countries participating by saying to them that, in the long term, and at the end of a new Treaty, they would be brought to contribute to the collective effort, this one not even being outlined. One of the stakes of Copenhagen was to outline this, postKyoto. To resolve this conference which seemed likely to fail, the skill consisted in mobilising the old technique of bargaining 'How much do you propose?' It worked wonders. In one night, about 30 States representing $80 \%$ of the world emissions, ${ }^{11}$ contracted within a month, to declare the summit of their intentions. Big catch, since inside the net were the USA and the large emergent countries. One year later, Cancun had only to take note. ${ }^{12}$ It was interpreted as an abandonment of a design of a 'top-down' climatic governorship imposed by the top like Kyoto regime, for the benefit of a 'bottomup' approach consisting in coordinating and giving coherence to the proposals emanating from the bottom and translating the strength of national sovereignty. But realism made things advance.

\subsection{The emissions allowances trading}

The construction of an international climatic architecture returns to the choice of instruments of economic management, their extent of application to the methods of assessment and beyond that to the criteria justifying them. It is Kyoto that created the emissions allowances trading system with their extension, particularly through the Mechanism of Clean Development and of Joint Implementation. 
Concerning approximately $5 \%$ of the world's total emissions, this mechanism thus has the appearance of a laboratory, although in Europe it relates to $43 \%$ of all emissions, half coming from the sector of electricity production. This engendered the main part of all criticisms addressed to the world architecture. The literature concerning it is disproportionate compared to its true importance.

It came into force late (2005) because of the slowness of all ratifications. The US volte-face (treaty signed but not ratified) was assumed by three presidents - Clinton, Bush and Obama - revealing a structural posture justified from the start by a refusal to buy quotas from the state that would have been the principal salesman - Russia - but in the long term by a refusal to consider a questioning of the 'American way of life'.

In Europe only 27 engaged in the mechanism leaving the diffuse sector (habitat, transport and agriculture) to be allocated to the 12,000 large sources of listed emissions including 1100 in France. The principle of the emissions allowances trading consists in allocating quotas of $\mathrm{CO}_{2}$ emissions to States on an international scale, to companies on a national scale, free at the moment, which they can then exchange. Each $\mathrm{CO}_{2}$ emitter must then make sure that it holds as many emissions licenses as it will emit. If not, then it must reduce its emissions or buy licenses. Conversely, if its efforts to control emissions enable a surplus of licenses, it can put them on sale. The mechanism works in two sequences ('cap-and-trade'). Initially, the political decision makers (responsible for the EU) fix the total volume of emissions authorised by distributing them to countries which then allocate them to their companies. Second, if the allowance does not meet the needs, companies can exchange between themselves. Europe joined with this mechanism, because the alternative - a unique European carbon tax - involved tax policy, and would have required unanimity difficult to obtain. Such a market has a particular nature. It is adaptive to the Plan (allocation of all licenses), in the sense that the flexibility introduced allows it to carry on. It eliminates discrepancies between the initial allocation and needs of companies. It does not control anything in the climate affected only by the physicchemical relations. It is the political decision maker who exercises control by fixing the amount of authorised quotas. It is a tool at the service of the political authorities to guarantee their decision. ${ }^{13}$

These markets are very controversial. They are accused of supporting 'escape carbon' by encouraging industrialists to move to less constraining areas not concerned with the allocation of quotas; of supporting the massive intrusion of speculation into carbon finance; of creating victims of computer fraud; or doubtful certification of Clean Development Mechanisms. This led UNO to audit the accounts and to suspend these operations temporarily, and the VAT scam within the EU.

All these criticisms are well founded, although they are not all of the same scope. The 'escape carbon' favoured by delocalising firms allows groups to sell unused quotas within the same allocation zone while emitting in a zone not subject to quotas. There are additional emissions therefore, reaching the climate. These 'escapes' are low in number; a few percent (Guesnerie, 2010); It is obviously not possible to raise the constraints to the extent that some could withdraw from it. It is advisable to lower the ceiling of allocated quotas a little to anticipate and counterbalance the effect of the 'escapes'. The carbon market allows anyone to become a purchaser of the resold quotas. 'Carbon finance' rushed to take on what it saw as an opportunity to speculate in creating derivative markets boosted by the possibility of organising the mechanism of futures options in the long term. One can be indignant at the creation of this speculative niche, but it must be recognised that this mechanism, remaining locked within a zero sum game, does not give 
rise to any new emissions and therefore has no effect on the climate (Martin and Rocard, 2010). The ultimate payer, being the not very virtuous firm which prefers buying additional quotas rather than modernising, will certainly pay dearly to be able to feed carbon finance. The swindles on VAT or certification deserve investigation and sanctions, but do not call the mechanism into question. These non-essential criticisms create a problem of hiding the true responsibility of the political decision makers who fix the quantity of distributed quotas. The ceiling controls and exchange guarantee regulation by reallocating the allowances of badly affected quotas. The signal-price emerging from this market does not reflect a tonne price for carbon, but a laxity of the decision makers and a poor allocation of quotas. There are three key questions - the quantity of GGs emitted, who emits them and who pays? Only the answer to the first question is important for climate regulation. This is where it all happens. The two other questions concern controls by a mechanism with zero sum and are thus without significant effect on the climate, because the gases which are emitted into the atmosphere have neither a National flag nor a Company logo. The ultimate payer is neither the State nor the consumer, but the Company weaker in economical emissions technology. The criticism of these markets on this basis leads to poor targeting on officials and contributes to exempting them.

In France, the Juppe-Rocard project for the introduction of a carbon tax for the 'diffuse' sector failed before the obscure arguments of the Constitutional Council. In the face of governmental refusal to accept a level of tax of $50 €$ per tonne, the Commission suggested a level of $17 €$ to align it with the signal-price coming from the market of negotiable licenses, pretending to believe that the two concepts were homogeneous. Michel Rocard recognised several months later ${ }^{14}$ that this signal-price was not the price of a tonne of carbon since the quotas were distributed free on these markets. The signalprice thus more properly reflects the good or poor allocation of resources by the political decision makers. If a tension is observed in the market, then the initial allocation can be readjusted. If many quotas are allocated, the price will tend to drop. That can be corrected by the intervention of those deciding the number of quotas to be allocated. The regulation is done by quantity and not by price, this is why it comes from the decision to grant quotas - the cap - and not on the price which comes from their exchange - the trade.

\subsection{May the World standard be applied everywhere?}

The setting-up of climate architecture initially requires thinking about the world such as it really is and not as we would like it to be. In short, we all dream about a Kantian world but we must act in a world as described by Hobbes or Aron, otherwise reality will catch up with us. Copenhagen illustrated this: it revealed the return of sovereignties, divergent interests and not the image of a 'planetary village' but a divided world made up of States with singular trajectories. It is necessary to cease to believe that the real existence of problems with a planetary size - like climate - could make us think that a world economy would exist already and that identical standards could apply from one end of the planet to the other (level of tax, percentage of reduction of GGs) without considering the national specificities or development trajectories. The same level of tax would not have an identical impact in Brazil, China or the USA. That means abandoning the idea of a total governorship for climate and an authority which would govern all, and define in detail what must be undertaken by each, and to have on the contrary the desire to superimpose any governance on a scale of homogeneity. ${ }^{15}$ 
The mechanics do not matter - in any event UNO will build a world architecture. It will succeed only if it is perceived, not as a constraint, but more like a lever. The proposed mechanism must be an incentive. This supposes an immense effort to help Southern countries to jump the stage of intensive use of fossil energy. It is advisable to think about changing trajectories by requiring massive transfers of technologies and sharing of knowledge, obliging Northern countries to derogate from the principle of intellectual property in order to gain in energy effectiveness and to develop renewable energies to implement a transition towards a decarbonised economy.

\section{Conclusions}

We must be aware that a large part of the effort can come from the international climatic architecture. Since 2005, we can see the formation of a cooperative process between six countries (USA, Australia, India, China, Japan and South Korea) to coordinate their efforts on the climate by sharing experience and transferring knowledge. This cooperation is at its highest level between China and the USA. Similarly, we must note the recent adoption by 70 cities of the 'Mexico City pact', committing them to adopt quantitative objectives and a verifiable fall in their $\mathrm{CO}_{2}$ discharge. In the same way, several US States took the initiative to organise markets of negotiable quotas of emissions, independently of any international engagement of the USA. China is on the point of organising one on a national scale. It is necessary to accept and support the bilateral initiatives, even simply the solitary and exemplary not being necessarily in a totally negotiated system.

Independently of any criterion retained, if one wants to keep in mind the concerns of justice and equity, one cannot miss drawing inspiration from the principle of 'reduction and convergence' which means that it is at the same time necessary to reduce the total emissions of GGs and to decrease the gap of emissions per capita of the inhabitants of the planet. Failing this, many countries will slow down the process of negotiation.

It is about crossroads negotiation coming back to the importance given to time, to North-South relationships, and to questioning the constructed models of development. Balance between development and respect for the environment is not arbitrated in the same way in the South and the North. With such stakes, it is advisable to rehabilitate the long time and what must accompany it, planning on the condition of the short term influences of the traditional political authorities. ${ }^{16}$ In the absence of this long vision, the immediate evils like misery, illiteracy, the absence of a health system or infrastructures will be in conflict with the timing of climate safeguarding.

The climatic threat is often combined with the spectre of the shortage of resources. This is a mistake. Climatic change is fed by excessive use of certain resources, particularly the carbonaceous ones at the heart of harmful emissions. The shortage of these resources like crises or wars would be beneficial to the climate. In his interaction with the environment, man acts on the resources that he rarefies (action on the upstream), and by using them he ejects pollutants or disturbers which degrade the surrounding ecosystem (action on the downstream). The climate problem concerns the downstream. Moreover, nothing indicates that it is necessary to adhere to the pre-Malthusian ${ }^{17}$ thesis $^{\text {in }}$ of exhaustion of resources. We are told that resources would be limited and comparable to a stock, fixed once for all, and condemned to exhaustion, quickly forgetting that the principal creator of these resources was always man and that oil would be little without 
the spark-ignition engine, uranium nothing without control of the atom, and the rare earths useless without mobile telephones. The challenge is to know if the stock of resources will develop as quickly as the needs of man and if its exploitation remains compatible with the survival of viable ecosystems allowing the maintenance of human activity on the planet.

Climate problems and the negotiations accompanying them brought forth a new collective actor, the scientific community converting to the status of world expert. Far from letting themselves be exploited, they learned how to be essential to the policies, but had in return to be exposed to the public polemic, from which they were not spared. The future will say if science, entering the arena of the debates of the city, will leave from there enhanced or damaged. They play there a legitimate part.

Climatic degradation calls strongly for action on the operating modes of our societies. From the modes of production to types of consumption, it is advisable to question the whole life style. The research on a climate-compatible mode of accumulation will encounter powerful lobbies which are at the heart of the economic system. It would be tempting of course to affirm that it would suffice to change the system to save the climate. Admittedly, but if the change of system is not put in the political diary quickly enough what will become of the climate? Does the proposal result in undervaluing the urgency of the climatic threat? Do we have to use the climate to delegitimise the system $?^{18}$ It would be easy to forget that the climate is a common good for humanity, therefore the business of all. Should we then be required to show an anti-system passport to bear this concern? By definition the defence of a common good cannot be the business of a minority. It can advance only around broad mobilisations.

\section{References}

Bourg, D. and Whiteside, K. (2010) Vers une démocratie écologique - Le citoyen, le savant et le politique [Towards an Ecological Democracy - the Citizen, the Scientist and the Policy], Seuil, Paris, 106p.

Brunel, S. and Pitte, J-R. (2010) Le ciel ne va pas nous tomber sur la tête [The Sky will not Fall on our Head], Jean-Claude Lattès, Paris.

Crutzen, P.J. and Stoermer, E.F. (2000) 'The Anthropocene', Global Change, IGBP Newsletter, 41 May, pp.17-18.

Dahan, A., Aykut, S., Buffet, C. and Viard-Crétat, A. (2010, February) 'Les leçons politiques de Copenhague - Faut-il repenser le régime climatique? [The Political Lessons of Copenhagen is it Necessary to re-think the Climate Regime?]', Koyré Climate Series, No. 2, 45p.

Guesnerie, R. (2010) Pour une politique climatique globale - Blocages et ouvertures [for a global climatic policy - Blockages and openings], Editions Rue d'Ulm, Paris, pp.39-40.

Le Bras, H. (1994) Les limites de la planète - Mythes de la nature et de la population [The Limits of the Planet - Myths of Nature and Population], Flammarion, Paris, 351p.

Lieberthal, K.G. (2009, September) US-China Clean Energy Cooperation: The Road Ahead, Brooking Institution, 35p.

Martin, Y. and Rocard, M. (2010) 'Pour une fiscalité verte progressive sur les énergies non renouvelables [For a Progressive Green Taxation on Non-Renewable Energies]', Le Monde, 9 January.

Rocard, M., Bourg, D. and Augagneur, F. (2011) 'Le genre humain menacé [Threatened Mankind], Le Monde, 3-4 April.

Rosanvallon, P. (2009) 'Sortir de la myopie des démocraties [To get the Democracies out of Myopia]', Le Monde, 7 December. 
Schelling, T. (2010) 'Un faisceau d'incertitudes [a Beam of Uncertainties]', in Touffut, J-P. (Ed.): Changement de climat, changement de l'économie? [Climate Change, Economy Change?], Albin Michel, Paris, pp.67-84.

Stern, N. (2007) The Stern Review: The Economics of Climate Change, Cambridge University Press, Cambridge, 700p.

Tirole, J. (2009) Politique climatique: une nouvelle architecture internationale [Climatic Policy: a new International Architecture], Conseil d'Analyse Économique/La Documentation Française, Paris, 357p.

\section{Notes}

1 Cf. the contribution of Nobel Prize 2004; Schelling, 2010.

2 In France, the debate lost its virulence after the report of the Science Academy, The climatic change, 26 October 2010, p.21, had invalidated the theses of climate-sceptics, while carefully avoiding quoting IPCC.

3 For example Jean Jouzel, vice-president of IPCC, answering the question of a journalist "How can one state a probability on reheating?": "Look at all the confusion. One does not say in any way that $90 \%$ of the recent reheating is related to human activities, as is too often heard. We say that there are nine chances out of ten that a big part of this reheating is related to human activities", Le Figaro, 19 March 2010. It will be noted, beyond prudence in the matter, that the debate with the climate-sceptic is essentially brought back to the appreciation of this 'big part'. We are far from negation of the tendency of reheating.

4 It is enough to remember how, at the time of the 'Glorious Thirty' experts in social engineering explained that unemployment beyond $5 \%$ or $6 \%$ would produce sufficiently noxious effects as to cause the collapse of any society.

5 The president of IPCC, Rajandra Pachauri, expressed interest in this research orientation. Cf. Time, 1 December 2009.

6 Since 2009 this cooperation has intensified and given important agreements (cf. Lieberthal, 2009).

7 With the fable of 'The Cicada and the Ant', Jean de La Fontaine had already opened the framework of reflection. It is not certain that the abundant literature, strongly mathematical on the discount rate, made him take decisive steps.

8 Thus, Claude Allègre tries to convert his scientific defeat into political victory.

9 To create pressure on US public opinion at the time of the Copenhagen Summit, Obama tried to reactivate the Clean Air Act in mobilising the Federal Environmental Protection Agency (EPA).

10 This risk of global ecology had been perceived very early (cf. Le Bras, 1994).

11 Only $25 \%$ of the countries from Appendix 1 of Kyoto had ratified the protocol.

12 Depending on the State, the commitment relates to results (reduction of emissions), to means (decrease in energy or carbon intensity) and returns to date references as well as different horizons. That makes comparisons difficult.

13 La régulation des marchés du $\mathrm{CO}_{2}$, (Regulation of the markets of $\mathrm{CO}_{2}$ ), Report entrusted to Michel Prada, honorary Inspector General of Finances, 2010, p.227, French Republic. One can read: "The European market of $\mathrm{CO}_{2}$ is a device, created by public power, whose objective is to guarantee the reduction of emissions at a lower cost", p.1, or: "the European market of $\mathrm{CO}_{2}$ is today the only tool which guarantees a level of optimised reduction of GG emissions within a European perimeter covering 27 Member States", p.14.

14 The simplest way would consist of prohibiting the resale of quotas allocated to any entity not benefiting initially. The market would thus be closed to any intrusion of 'carbon finance'. The signal-price which would emerge would not be subject to speculation and would provide to the decision makers exact information in order to continue to lower the ceilings of the allocated quotas. 
15 It is essentially about what we find in the 'Tirole Report' (Tirole, 2009).

16 We will note the rise of reflections on this subject leading in this direction (Rosanvallon, 2009; Bourg and Whiteside, 2010; Rocard et al., 2011).

17 Malthus on the contrary has the appearance of a precursor for growth theories and its famous comparison on the dynamics of needs and resources; he never predicted the exhaustion of those since they were supposed to show an arithmetic growth, slower than the geometrical growth of needs. The thesis of the exhaustion of resources is inspired rather by the physiocratic school of François Quesnay and with his search for a golden age of an ideal level of production for a given population and structurally compatible with the conditions of its reproduction.

18 The mechanism of exploitation of man by man, as well as the assessment of colonialism or imperialism, suffice already to perhaps delegitimise it. 